\title{
Dissertações e teses produzidas entre os anos 2000 e 2017: uma contribuição para o cotidiano escolar
} Dissertations and theses produced between the years 2000 and 2017: a contribution to school daily life

\section{Disertaciones y tesis producidas entre los años 2000 y 2017: una contribución a la vida escolar diaria}

\author{
Alda Romaguera ${ }^{1}$ \\ Ana Cristina Silva ${ }^{1}$ \\ Magda Bellini ${ }^{1}$ \\ Vinícius Santos ${ }^{1}$
}

DOI: http://dx.doi.org/10.20435/serie-estudos.v26i56.1492

\begin{abstract}
Resumo: Este artigo apresenta as contribuições teórico-metodológicas de um Programa de PósGraduação na área de Educação Escolar (PPGE). Problematiza as metodologias e orientações de escritas conservadoras, para tecer novas formas de pesquisar com as abordagens teóricas e os processos de criação dos cotidianos escolares. Analisa as dissertações e teses defendidas no Programa abrangendo os dezessete primeiros anos do século XXI. Tal análise da produção de sentidos em Educação fundamenta-se na abordagem qualitativa, de tipo bibliográfico-documental, e escolhe como lugar investigativo as relações com o conhecimento vivido. Debruça-se sobre a produção acadêmica deste PPGE e dele recolhe diferentes sentidos que se podem produzir, ao aproximar o campo conceitual dos cotidianos com as práticas inventivas recolhidas nas dissertações e teses. Os resultados apresentados por esta pesquisa evidenciam, pelas escritas e metodologias abordadas, um exercício de práticas pedagógicas diferenciais e transformadoras nos/dos/com os cotidianos de escolas públicas da cidade de Sorocaba, SP, e região.
\end{abstract}

Palavras-chave: Educação; cotidiano escolar; práticas pedagógicas.

Abstract: This article presents the theoretical and methodological contributions of a Postgraduate Program in the Area of School Education (PPGE). It questions the methodologies and orientations of conservative writings to weave new ways of researching with the theoretical approaches and the creation processes of the school's daily life. It analyzes the dissertations and theses defended in the Program covering the first seventeen years of the 21st century. Such an analysis of the

\footnotetext{
${ }^{1}$ Universidade de Sorocaba (UNISO), Sorocaba, São Paulo, Brasil.
} 
production of meanings in Education is based on the qualitative approach, of bibliographicdocumental type, and chooses relations with the knowledge lived as an investigative place. It focuses on the academic production of this PPGE and gathers different meanings that can be produced by bringing the conceptual field of everyday life closer to the inventive practices collected in dissertations and theses. The results presented by this research, through the approached writings and methodologies, show an exercise in differential and transforming pedagogical practices in/of/ with the daily lives of public schools in the city of Sorocaba, SP, and region.

Keywords: Education; school life; pedagogical practices.

Resumen: Este artículo presenta las contribuciones teóricas y metodológicas de un Programa de Posgrado en el Área de Educación Escolar (PPGE). Cuestiona las metodologías y orientaciones de los escritos conservadores, para tejer nuevas formas de investigación con los enfoques teóricos y los procesos de creación de la escuela todos los días. Analiza las disertaciones y tesis defendidas en el Programa que abarca los primeros diecisiete años del siglo XXI. Tal análisis de la producción de significados en Educación se basa en el enfoque cualitativo, de tipo bibliográfico-documental, y elige como lugar investigativo las relaciones con el conocimiento vivido. Se centra en la producción académica de este PPGE y reúne diferentes significados que se pueden producir al acercar el campo conceptual de la vida cotidiana a las prácticas inventivas recogidas en disertaciones y tesis. Los resultados presentados por esta investigación muestran, a través de los escritos y las metodologías abordadas, un ejercicio de prácticas pedagógicas diferenciales y transformadoras en/de/con la vida cotidiana de las escuelas públicas en la ciudad de Sorocaba, SP, y región.

Palabras clave: Educación; cotidiano escolar; prácticas pedagógicas.

\section{INTRODUÇÃO}

Neste artigo, apresentamos alguns dos resultados do projeto de pesquisa denominado Cotidianos escolares e produção de sentidos éticos, estéticos e políticos $^{2}$, realizado pelo Grupo Ritmos: Estética e Cotidiano Escolar (GREeCE) ${ }^{3}$, na Linha de Pesquisa Cotidiano Escolar, do Programa de Pós-Graduação em Educação (PPGE) da Universidade de Sorocaba (UNISO), SP.

No caso específico deste projeto, buscamos abordar os cotidianos vividos pelos praticantes pensantes (ALVES; FERRAÇO; GOMES, 2019), aqui representados por profissionais da Educação que, em meio às múltiplas e complexas redes tecidas em suas duplas trajetórias de pós-graduandos e atores dos cotidianos escolares, expandem suas práticas pedagógicas. Ao tomar contato com esta

\footnotetext{
2 Projeto de pesquisa desenvolvido entre os anos de 2018 e 2019, como parte das atividades do GREeCE.

${ }^{3}$ O GREeCE desenha-se como um coletivo que, ao estudar, pesquisa e produz pensamentos e artefatos culturais.
} 
experiência, não mais se deixam capturar por recursos didáticos que tendem a apostilar conhecimentos e nem por aulas que se configuram como monótonas repetições (ALVES; FERRAÇO; GOMES, 2019).

Observamos que os profissionais de Educação, enquanto realizam a PósGraduação nesta Linha de Pesquisa, aproximam-se de inúmeras práticas, tais como: oficinas, vídeos com enfoque ambiental, pedagógico e político, que são analisados, discutidos e reelaborados para pensar as práticas pedagógicas cotidianas realizadas, problematizando os vários aspectos da Educação que consideramos indissociáveis e imprescindíveis: cidadania, ética e justiça social.

Nosso objetivo inicial, ao realizar esta pesquisa, é o de trazer visibilidade acadêmica e pública às dissertações e teses defendidas no período compreendido entre 2000 e 2017, no Programa. Com este gesto, passamos a problematizar metodologias e orientações de escrita de pesquisas, para tecer novas formas de entendimento das teorias e dos processos de criação e resistência, por meio de conhecimentossignificações ${ }^{4}$ (ALVES; FERRAÇO; GOMES, 2019), como uma das formas de produção de outros modos de existência.

Tal projeto busca outras possibilidades de movimentos, de significações, de combate à burocracia e à institucionalização. Iniciamos nosso percurso para ir ao encontro de:

[...] uma metodologia de pesquisa que abra mão das certezas, mas não do planejamento; de uma vontade exclusiva de explicação e interpretação, mas não da análise da/na produção dos dados, eventos e conhecimentos; que esgote a vivência 'em si' nos cotidianos dos estudantes e/ou dos pesquisadores para apostar em uma experimentação em devir; que se faça por composições à deriva, mutante a cada acontecimento, no encontro entre pessoas e objetos e sensações; que se movimente por uma poética da produção de sentidos. (ROMAGUERA; ANDRADE, 2020, p. 24).

Nós nos debruçamos sobre a produção acadêmica deste PPGE e dele recolhemos diferentes sentidos que se podem produzir, ao aproximarmos o campo conceitual dos cotidianos com as práticas inventivas recolhidas nas dissertações e teses.

A partir do campo conceitual dos cotidianos escolares, organizamos dois movimentos para a escrita deste artigo; no primeiro, realizamos o levantamento

\footnotetext{
${ }^{4}$ Os autores optam por grafar algumas palavras em junção e em itálico para produzir sentidos que se deslocam de cada vocábulo e se potencializam nessa aproximação.
} 
dos dados, que geraram as informações apresentadas nos quadros adiante. No segundo movimento, os pesquisadores optaram por trabalhar com o cotidiano escolar tomando-o como um dos campos de produção de conhecimento e de investigação em Educação, nos dizeres de Alves, Ferraço, Gomes (2019), considerando-os enquanto espaçostempos de acasos, de multiplicidades e de diferenças. Ao fazer esta opção, dialogamos com algumas das referências nos Estudos do Cotidiano Escolar, indicadas ao longo deste texto, que movimentam as produções acadêmicas realizadas na referida linha de pesquisa.

Ressaltamos que tal perspectiva teórica se espraia nas nossas produções acadêmicas, seja nos escritos divulgados em periódicos e capítulos de livros, seja naquelas que se encontram com as pesquisas embasadas pelos Estudos do Cotidiano Escolar. Entendemos, com Goergen (2017), que a formação humana pautada, quase que exclusivamente, na dimensão da racionalidade pode, como nos dirá Freire (2018), caminhar de mãos dadas unindo decência com boniteza para o exercício da vida coletiva. Esse movimento trouxe pistas para aquilo que não nos captura pelo conservadorismo ainda presente nas pesquisas em Educação, mas nos torna aptos/as ao combate dos modelos já existentes e nos apresenta a outros modos de viver e pensar cotidianos escolares.

\section{COTIDIANOS ESCOLARES E PRODUÇÃO DE SENTIDOS}

Iniciamos, no ano de 2018, um levantamento de dados que incluía todas as dissertações e teses defendidas no Programa, utilizando como ponto de partida uma pesquisa-piloto, realizada em 2015, pelo Grupo de Estudos e Pesquisa em Cotidiano Escolar (GEPECE); tal exercício foi organizado tomando como critério a sua inserção nas diferentes linhas de pesquisa, abaixo indicadas. Deste piloto, resultou a dissertação de Rezende (2016). Ampliamos os dados desta pesquisa com a inserção da produção acadêmica dos anos de 2016 e 2017. Obtivemos os seguintes dados: 
Quadro 1 - Produção acadêmica do PPGE - anos 2000 a 2017

Dissertações e Teses $\quad$ Linha Cotidiano Escolar (CE) Percentual CE

\begin{tabular}{|c|c|c|c|}
\hline Mestrado & 355 & 167 & $47 \%$ \\
\hline Doutorado & 50 & 18 & $36 \%$ \\
\hline TOTAL & 405 & 185 & $46 \%$ \\
\hline
\end{tabular}

Fonte: Grupo Ritmos - Estética e Cotidiano Escolar, 2018.

O Quadro 1 apresenta na primeira coluna, em quantidades, a produção acadêmica total do período a que se refere. Podemos perceber que as defesas de dissertações são três vezes maior que as de teses, fato este que se deve ao tempo de criação dos cursos; o doutorado no Programa ${ }^{5}$ foi criado apenas no ano de 2008. Na segunda coluna, observa-se que a Linha de Pesquisa Cotidiano Escolar (CE) foi a mais procurada no programa neste período. A terceira coluna evidencia a concentração de $47 \%$ das dissertações e 36\% das teses defendidas. Se tomarmos como referência o total das produções acadêmicas, apreende-se que a Linha CE reuniu quase a metade destas (46\%).

É importante observar que as linhas de pesquisa do PPGE 6 passaram por diversas mudanças de nomenclatura desde sua criação. Entre os anos de 1997 e 1999, recebia o nome de Mestrado em Educação de Ciências. No ano 2000, a denominação era Mestrado em Educação, e suas linhas de pesquisa passaram a ser Construção do conhecimento nas relações escolares e Escola e Trabalho e Políticas educacionais, permanecendo assim até o ano de 2007, quando se reestruturou novamente e, a partir de 2008, com a recomendação e autorização para o início do doutorado em Educação, passou a ser denominado de Programa de Pós-Graduação em Educação, com as seguintes linhas de pesquisa, para mestrado e doutorado: Cotidiano Escolar; Educação Superior; História e Historiografia: políticas e práticas escolares; Trabalho Docente. Na busca por um melhor alinhamento das linhas de pesquisa, no ano de 2015, elas passaram a ser nomeadas: Cotidiano Escolar e Educação Superior e História e Historiografia: políticas e práticas escolares, permanecendo assim até o presente momento.

\footnotetext{
${ }^{5}$ Disponível em https://sucupira.capes.gov.br/sucupira/.

${ }^{6}$ Programa de Pós-Graduação em Educação - Universidade de Sorocaba (UNISO), SP.
} 
Com os dados da produção acadêmica em mãos (Quadro 1), nós nos dedicamos às leituras dos resumos das 185 dissertações e teses defendidas na linha de pesquisa CE. A decisão de busca nos resumos foi tomada por estarmos na fase de levantamento das informações necessárias para apresentar o percurso científico de tais produções acadêmicas. Fizemos as leituras em conjunto, em reuniões do grupo de estudos, nas quais contávamos também com as vivências de doutorandos/as que conheceram os autores/as e acompanharam os processos de algumas destas produções.

Após esta análise exploratória nos resumos das pesquisas, elencamos três questões para orientar os próximos passos: de quais espaçostempos escolares emanam estas pesquisas? As argumentações se constroem com quais saberesfazeres (ALVES; FERRAÇO; GOMES, 2019)? As metodologias encontram conhecimentossignificações?

Das 185 produções observadas, quando submetidas a estas três questões norteadoras, obtivemos os seguintes dados:

Quadro 2 - Produção acadêmica - Linha de Pesquisa Cotidiano Escolar (CE)

\begin{tabular}{|c|c|c|}
\hline Produção Acadêmica & Linha Cotidiano Escolar (CE) & Recorte \\
\hline Mestrado & 167 & 40 \\
\hline Doutorado & 18 & 6 \\
\hline TOTAL & 185 & 46 \\
\hline
\end{tabular}

Fonte: Grupo Ritmos - Estética e Cotidiano Escolar, 2018.

O Quadro 2 apresenta o segundo recorte da pesquisa, que doravante passa a analisar 46 produções acadêmicas, da Linha CE. Este recorte revelou que, deste novo total, 57\% (cinquenta e sete por cento), ou seja, 26 (vinte e seis) teses e dissertações foram orientadas pelo professor Marcos Reigota. Entre os movimentos que constituíram e alicerçaram a história da Linha de Pesquisa CE, destacamos a relevância deste professor pesquisador. Reigota desperta nos alunos/as outro perfil de pesquisadores, deslocando-os/as para uma pesquisa viva, na perspectiva ecologista de Educação, alicerçada na pedagogia freireana, em que a teoria dá o aporte para o entendimento e atuação ética no cerne da sociedade.

Para elencar algumas de suas orientações, citamos a dissertação de Germano (2006), que, a partir do trabalho como supervisora pedagógica do programa de 
Educação de Jovens e Adultos, passa a acompanhar as histórias de vida dos alunos idosos, relacionando os conceitos da pedagogia freireana e salientando a leitura de mundo em sua narrativa. A pesquisadora Sinto (2013) apresenta, a partir da experiência como professora de Artes em uma escola estadual, as narrativas, sons e imagens de um cotidiano escolar. Apresenta ainda sua biografia (REIGOTA; PRADO, 2008), refletindo sobre a constituição de sujeito da história (FREIRE, 2018). Silva (2017), escreve um texto construído de forma não linear, cujas cartas enviadas e recebidas se tornaram narrativas ficcionais, inclusive aquelas enviadas a Paulo Freire. Elas surgem após a capacitação realizada pela pesquisadora em Sorocaba, SP, no projeto Red Latinoamericana-Europea de Trabajo Social Transnacional (ReLETran).

Quando analisadas sob o prisma da questão: de quais espaçostempos escolares emanam estas pesquisas? Observou-se que 63\% (sessenta e três por cento) das produções acadêmicas tiveram como locus a escola pública nos seus múltiplos segmentos da educação básica e do ensino superior; os pesquisadores são atores praticantespensantes, professores e professoras, gestores e gestoras das redes municipal e estadual.

Entre as pesquisas analisadas, citamos Barchi (2006), que aborda e discute os discursos realizados nas conversas cotidianas sobre as pichações nas escolas, sob a possibilidade de uma educação ambiental de enfoque libertário. Para este autor:

A pichação é uma forma de escrita feita nas paredes e carteiras escolares, muitas vezes com caracteres indecifráveis e sempre mutáveis, causando, no mínimo, desconforto, por não serem passíveis de compreensão, assimilação ou aniquilação. Mas ela também pode ser considerada arte e intervenções políticas anônimas, cujos autores veem a escola como um suporte. (BARCHI, 2006, p. 8).

Machado (2014) apresenta inspiração, conteúdo e leveza, trazendo Pina Bausch para adentrar o cotidiano escolar. A pesquisa relata o processo criativo de um percurso pedagógico, que coleciona nas/das histórias do cotidiano o trabalho da professora/artista em dança-teatro, nas aulas de Arte com alunos/as do ensino fundamental, de uma escola pública no interior de São Paulo.

Ao tornar públicos os processos de potência inventiva e criativa destas dissertações e teses cujo universo é o cotidiano escolar, apostamos no aprimoramento dos professores/as, que promovem laços, redes e práticas pedagógicas e sociais com 
a vida comunitária das escolas, avivando as relações democráticas. Defendemos tais relações como uma possibilidade de instaurar uma poética da Relação que "parece mais evidente e mais 'enraizante', atualmente, do que uma política do ser" (GLISSANT, 2005, p. 37). Cada uma dessas produções acadêmicas aqui exemplificadas evidencia que as pesquisas em Educação podem praticar poéticas ao modo de metodologia, produzir sentidos e instaurar uma poética da Relação com cotidianos escolares na atualidade.

A frequência nos grupos de estudos Perspectivas Ecologistas e Grupo Ritmos: Estética e Cotidiano Escolar (GREeCE) mostra-se potente para o encontro das pesquisas com as vivências cotidianas, o que abre o espaço dialógico pautado na práxis educativa freireana. Destas pesquisas, recolhemos o gesto de inventar mundos, que perpassam a intenção de travar bons combates na área educacional. Pautadas por tais aspectos, as teses e dissertações analisadas na pesquisa trazem diferentes singularidades dos espaçostempos escolares.

Entre as metodologias observadas, destacam-se aquelas cujas práticas cotidianas são as de ouvir as pessoas, produzir narrativas, avizinhar-se da produção cultural e artística, vivendo a escola intensamente e convocando os leitores a assumir com Guattari (2011): "[...] a escrita como um campo vibracional onde cada palavra carrega em si força capaz de movimentos" (LIMA, 2014, p. 20).

Estes pesquisadores praticantespensantes buscam o respaldo teórico de autores/as cujos saberes produzem conhecimentossignificações com os temas abordados por cada um dos trabalhos, "tecendo novas formas de entendimento tanto das teorias com as quais trabalhamos quanto dos processos de criação e de resistência que acontecem com" (ALVES; FERRAÇO; GOMES, 2019, p. 1027). Tais autores definem as redes cotidianas de conhecimentossignificações tomando de Deleuze (2007) o conceito de acontecimentos

[...] que não se deixam representar e que, por sua dimensão ético-estético-política, potencializariam novos modos de subjetivação emergentes, movimentos coletivos de enunciação, outros territórios existenciais, que nos possibilitariam produzir formas de combater os modelos opressores do capital e todo e qualquer conservadorismo que, nos dias atuais, se mostram, sobretudo, na defesa de valores morais, sexistas, racistas, homofóbicos, xenófobos, entre outros que têm na diminuição da vida sua aposta maior (ALVES; FERRAÇO; GOMES, 2019, p. 1028). 
Alinhados com as redes cotidianas, apresentamos na Tabela gráfico abaixo o espectro de autores/as mais citados nas referidas teses e dissertações, objeto de análise do artigo:

Tabela 1 - Referencial Teórico

\section{Autores}

ALVES, Nilda

ALVES, Nilda; GARCIA, Regina Leite.

BENJAMIN, Walter

BRASIL

CERTEAU, Michel de

DELEUZE, Gilles

FOUCAULT, Michel

FREIRE, Paulo

GALLO, Silvio

GUATTARI, Félix

HATOUM, Milton

LARROSA, Jorge

OLIVEIRA, Inês Barbosa de

OLIVEIRA, Inês Barbosa de; ALVES, Nilda

REIGOTA, Marcos

SOARES, Maria Lúcia de Amorim

SPINK, Mary Jane Paris

Fonte: Elaboração própria

\section{Citações}

11

14

9

11

10

11

10

26

19

10

12

9

14

9

27

11

14

Os autores relacionados na Tabela 1 contribuem de forma direta com saberes transversais (Gallo, 2000), que possibilitam a instauração de novos saberesfazeres (ALVES; FERRAÇO; GOMES, 2019) no cotidiano das escolas, com diversas perspectivas teóricas.

Da rede de cotidianos, participam Alves e Garcia (2000), Alves (2016), Alves, Garcia e Oliveira (2015), Ferraço (2016) e Alves, Ferraço e Gomes (2019), nos estudos com produção de sentidos, e Mary Jane Paris Spink (2013; 2018), com estudos sobre as narrativas na psicologia social e as representações sociais. Nos estudos de ecologias inventivas, Godoy (2008), Reigota e Prado (2008), Barcelos (2012) e Guimarães (2015). Na construção de leituras de mundo, Freire (2019), 
entre outros, buscando estabelecer relações (próximas ou distantes) das autoras e dos autores citados com a pedagogia freireana.

Observou-se durante a pesquisa que, quando Marcos Reigota passa a compor o quadro de docentes do PPGE, seus orientandos, além das perspectivas teóricas evidenciadas acima, tomam contato com leituras de Friedrich Nietzsche, Gilles Deleuze, Félix Gattari, Jorge Larrosa, Michel de Certeau, Michel Foucault, Walter Benjamin, autores que contribuem na construção epistemológica em distintas áreas de conhecimento. Seus orientandos/as aproximam-se também de diferentes produtos culturais que passam a ser incorporados nas pesquisas, como as obras de importantes escritores (Milton Hatoum), cineastas (Kurosawa) e artistas (Bené Fonteles).

O enfoque dado à narrativa ficcional como metodologia direciona as lentes dos pesquisadores/as para aquilo que ainda não foi fotografado, para sentir o lugar, saber a história dos que não podem narrar, olhar de outras perspectivas para os fatos, potencializando todos os sentidos para o que ainda não foi dimensionado. Entre essas pesquisas, citamos Catunda (2013), que convida a conhecer os inúmeros cotidianos da Educação que existem entre nós e de como:

[...] permeiam o processo da própria vida, com ela se fundem e confundem. A biografia de cada um ocorre entre encontros que desenham paisagens (ambiências), vivências, experiências, imagens, músicas e sonoridades. São acontecimentos que estão muitas vezes fora dos compêndios pedagógicos, das grades curriculares, dos programas, dos conteúdos, ementas, mas, nem por isso são menos ativos ou menos educativos em nossas vidas (CATUNDA, 2013, p. 8).

A partir dessas vivências, que possibilitam o enriquecimento dos processos de desenvolvimento educacional, privilegiados pela visibilidade de múltiplos ângulos sobre as variadas dinâmicas, camadas sociais e necessidades emergentes em cada um de seus contextos, surgem estudiosos, autores, saberesfazeres da escola, em cooperação, amparando novos possíveis olhares com o cotidiano escolar e as práticas ali vivenciadas.

Beber de muitas fontes como um dos movimentos de pensar reflexivo sobre os formatos da pesquisa e dos pesquisadores que Nilda Alves sugere e que contempla, ainda, a "[...] ampliação do que é entendido como fonte, discutindo os modos de lidar com a diversidade, a diferença e a heterogeneidade, dos 
cotidianos e de seus praticantes, tanto quanto suas múltiplas relações" (ALVES, GARCIA, OLIVEIRA, 2015, p. 136).

\section{COM QUE COTIDIANOS ESTAMOS COM-VERSANDO?}

Esta pesquisa com-versa com os cotidianos escolares enquanto campo de pensamento e produção de conhecimentos, o qual se insere na área da Educação. Versa com os acontecimentos vividos nos cotidianos, que atravessam os espaços educacionais, sejam eles escolares ou não. O vocábulo com aponta para os saberesfazeres (ALVES; FERRAÇO; GOMES, 2019), que se constituem em ações-reflexões-ações nos cotidianos praticados/pensados com os atores de tais espaçostempos (CERTEAU, 1998), no contemporâneo.

Assumimos, da palavra "conversa", sua ação de versar com, em contraponto aos tantos modos de versar "por" e de versar "pelas" pessoas, tomando-as em separado como problemas de pesquisa, numa concepção enrijecida, que nos conforma entre sujeitos pesquisadores e objetos pesquisados. Ao fazer este gesto, deslocamo-nos para uma posição de escuta/fala/escrita que nos envolve com as comunidades em todas as outras produções de sentidos possíveis. E nos entendemos implicados nas subjetividades que se instauram quando são suspensos o julgamento e a interpretação como centralidades das pesquisas em Educação.

Tais deslocamentos e implicações se dão nas dissertações e teses que questionam, por exemplo, os dispositivos de controle de uma escola estadual, em especial uma escada que é profanada por meio de uma prática teatral, narrada na pesquisa de Almeida (2014), ou quando Pedro Gomes Lima, afirma a multiplicidade da creche "como lugar do viver coletivo, do cuidado do outro e a atividade pedagógica como acontecimento, uma experiência que ocorre no entre lugar, nas territorializações/desterritorializações do cotidiano escolar" (LIMA, 2014, p. 109), apresenta e faz refletir sobre alguns acontecimentos cotidianos numa creche municipal da cidade de Sorocaba, SP.

A professora ao catar piolho, assovia fora do tom; subverte a ordem e este piolho traz um território para o encontro humano, onde a professora é afectada e se aventura, produz educação menor que traz felicidade e alegria, longe da normalidade que petrifica. Desloca-se junto de Silvio Gallo (2008) e faz uma escolha política, que renega outras discussões e se permite atravessar por esse deserto. (LIMA, 2014, p. 67). 
A pesquisa de Falcão (2015), professora da rede pública estadual, na disciplina de Arte, partindo do projeto "Tempo de Arte: a criação enquanto ocupação do sensível", permite "pensar a Arte nos espaços-tempos praticados no cotidiano escolar" como uma possibilidade de mediação para sensibilizar os alunos e instituir outras maneiras de se constituir o tempo e o espaço para a Arte.

O que interessou particularmente o presente estudo foi a possibilidade de intervir no espaço e no tempo instituído para as aulas de Arte na escola, o que, em certa medida, não constituiu uma oposição ao instituído que nos é dado de antemão, mas sim em retirar do espaço e do tempo instituído o excesso de informação, enxergando neles o lugar e o tempo da arte. Ou seja, foi preciso divisar vazios no espaço e no tempo instituídos e neles inserir arte. (FALCÃO, 2015, p. 221).

Não se trata aqui de cantar com Buarque (1971) "todo dia ela faz tudo sempre igual $[. .$.$] ", denunciando em passagens rotineiras uma falta de novida-$ des, de acasos e de sobressaltos que temperam a vida das pessoas em situações vividas de ensino-e-aprendizagem. Antes, trata-se de abraçar com Freire (2019) um campo de estudos e pesquisas em Educação, que olham, escutam, sentem, pensam e buscam por intensidades do vivido, daquilo que saltita nas relações entre pessoas, ambientes, coisas, em espaços, escolares ou não.

Trata-se de assumir a condição plural na enunciação de tais cotidianos, múltiplos e moventes, sem nunca se repetir, embora em uma primeira mirada se capturem rotinas e repetições infindas nos dias letivos de salas de aula, ainda hoje. Trata-se de praticar a dúvida, de colocar-se "à espreita" com Deleuze (1988) e Hatoum (2013), e perguntar: e se?

Se os cotidianos são múltiplos, trazem, ao mesmo tempo, uma fermentação borbulhante de vivências, que são as partículas de singularidade de cada um e cada uma de nós como seres únicos, que percorremos nossas histórias e memórias.

Se somos seres de singularidade e se os espaçostempos (CERTEAU, 1998) do comum (HARDT; NEGRI, 2016), tais como as escolas, universidades e cidades, fazem-se na proliferação destas singularidades, é possível buscar nas nossas pesquisas os diferentes modos de ser-em-grupo, como sugere Guattari (2011)?

A crescente relevância e protagonismo das questões dos cotidianos escolares, de diferentes níveis e características sociais e educacionais, exigem que os conteúdos tradicionais previstos sejam revistos e ressignificados. Esta afirmativa 
toma por referência as observações dos cotidianos vividos tanto em nossas práticas docentes na formação de professores/as, e de outros profissionais de nível superior, quanto em nossas práticas como pesquisadores/as; constatamos que a formação humana carece da presença mais direta dos cotidianos vividos.

Diante desta constatação, procuramos identificar diferentes práticas pedagógicas, que contemplem as expectativas e os questionamentos das novas gerações de profissionais, entre eles, os professores e professoras de diferentes níveis de ensino, que podem ousar em pesquisas, abrem o padrão acadêmico linear e transbordam contribuições para as ações educativas no/dos cotidianos escolares.

Se nós não somos estanques, por que a escola haveria de ser? O cotidiano escolar é composto por diversas subjetividades que dialogam, através de diferentes "mundos" que se encontram e se inter-relacionam, perpassados um pelo outro, gerando uma verdadeira rede. Nessa rede, não cabem conhecimentos em "caixinhas", relações hierarquizadas, tempos divididos, subjetividades isoladas. É urgente pensar outra forma de se fazer esse cotidiano, onde todas essas questões sejam consideradas, com foco em todos os envolvidos nesse processo, sujeitos atuantes e conscientes de sua historicidade. (ALMEIDA, 2016, p. 108).

Percorrendo as dissertações e teses, percebe-se a notável contribuição do legado de Paulo Freire; sua obra mais citada é Pedagogia da Autonomia (2018), na qual o autor dialoga com os professores e professoras trazendo à baila questões que os direcionam para uma ação reflexiva sobre a prática educativa. Observa-se que as pesquisas apresentam outras possibilidades de cotidiano, espaçostempos criativos, resistentes e inventivos, onde esses praticantespensantes não se deixam capturar, reconhecendo que a "percepção de nossa historicidade só é possível através de um processo educativo baseado no diálogo, no qual educadores/as e educandos/as constroem o conhecimento, construindo-se também, enquanto sujeitos autônomos" (ALMEIDA, 2016, p. 87).

Paulo Freire amplia as possibilidades de pensar uma aprendizagem/ensinagem horizontal, pautada na dialogicidade, na atividade grupal, na reflexão crítica do educando/a, que vive e atua no mundo. A Educação assume, assim, seu caráter transformador, permeando questões gnosiológicas, políticas, estéticas e éticas, em especial na proposta do Círculo de Cultura e Diálogo, realizada no Recife, nos anos 1960, com a perspectiva de alfabetização como tomada de consciência da realidade social, de democratização da cultura. 
[...] em lugar de escola, que nos parece um conceito, entre nós, demasiado carregado de passividade, em face de nossa própria formação (mesmo quando se lhe dá o atributo de ativa), contradizendo a dinâmica fase de transição, lançamos o Círculo de Cultura. Em lugar de professor, com tradições fortemente "doadoras", o Coordenador de Debates. Em lugar, de sua aula discursiva, o diálogo. Em lugar de aluno, com tradições passivas, o participante de grupo. Em lugar dos "pontos" e de programas alienados, programação compacta, "reduzida" e "codificada" em unidades de aprendizado. (FREIRE, 1992, p. 111).

Vivendo e acreditando que é possível uma sociedade mais justa, solidária, em que homens, mulheres e outros gêneros que atravessam esses sejam entendidos como seres históricos, que todos devem se envolver na luta libertadora das amarras opressoras, Paulo Freire foi adentrando o universo das escolas, principalmente as públicas.

Ninguém pode estar no mundo, com o mundo e com os outros de forma neutra. Não posso estar no mundo de luvas nas mãos constatando apenas. A acomodação em mim é apenas caminho para a inserção, que implica decisão, escolha, intervenção na realidade. Há perguntas a serem feitas insistentemente por todos nós e que nos fazem ver a impossibilidade de estudar por estudar. De estudar descomprometidamente como se misteriosamente, de repente, nada tivéssemos que ver com o mundo, um lá fora e distante mundo, alheado de nós e nós dele. (FREIRE, 2018, p. 75).

Consideramos que as dissertações e teses defendidas no Programa demonstram que as discussões freireanas apresentam fortes relações com as questões atuais do cotidiano escolar vivido por seus praticantespensantes.

\section{CONSIDERAÇÕES}

Após a análise dos referenciais teóricos recolhidos das 46 dissertações e teses que compõem esta pesquisa, obtivemos um levantamento de colaboradores que com-versam com o campo do cotidiano escolar. O trabalho investigativo aqui apresentado tem se ampliado nos anos subsequentes a esta coleta de dados; a produção acadêmica defendida nos anos de 2018 a 2020 consolidam nosso enfoque e reforçam a acolhida a professores e professoras de diferentes níveis de ensino da rede pública de Sorocaba, SP e região. Percebemos que a cada ano letivo renova-se o desejo e o encantamento de pesquisar com esta perspectiva e 
recebemos convidados/as que se aproximam dos grupos de pesquisa para iniciar seus estudos em educação.

São exemplos dessas produções a dissertação de Martins (2019) e as teses de Machado (2019) e Ramos (2018), entre outras. Consideramos que o resultado se vincula ao nosso crescente incentivo à experimentação de práticas pedagógicas diferenciadas e à constante interação entre nós. Temos observado que os professores e professoras que nos procuram buscam aprofundar, trocar suas experiências e práticas pedagógicas e ressignificá-las com referenciais teóricos e metodológicos contemporâneos e voltados à vida cotidiana. Não se trata, portanto, de buscar o desenvolvimento de métodos pedagógicos específicos ou modelos prontos, mas sim de experimentar outros modos e formas possíveis de pesquisar no/do/com o cotidiano das práticas pedagógicas.

Estas referidas práticas pedagógicas são consideradas inventivas na medida em que buscam, por meio de atividades lúdicas, teatrais, de percepção sonora, visual, enfim, da expressão do corpo, da criação artística e da invenção, ressignificar o cotidiano escolar produzindo novos sentidos dentro e fora da escola. Consideramos que o modo convencional de oferecer cursos de formação para educadores/as com ênfase nos conteúdos acaba por inibir a ampliação mais efetiva deste aprimoramento, que tanto compromete a qualidade do ensino público no país. Por este motivo, procuramos pesquisar práticas pedagógicas que incluam também o debate teórico, metodológico e político dos temas e das problemáticas dos estudos no campo da Educação.

Defendemos, com as pesquisas analisadas, que é possível pensar e praticar metodologias que se relacionam com uma poética da produção de sentidos. Apostamos na produção de sentidos com práticas pedagógicas (auto)identificadas como inventivas, que possibilitam a ampliação de uma poética da Relação nos/ pelos cotidianos escolares; que enfatizem a relação com a vida cotidiana dos seus atores (professores, crianças, comunidade escolar etc.), com suas características e demandas locais; que gerem possibilidades e alternativas de mudanças e/ou de soluções para os desafios da contemporaneidade.

Buscamos, nas referidas práticas, expressões dos cotidianos escolares em conexão com as ecologias inventivas e com manifestações artístico-culturais, que contemplem as expectativas e questionamentos das novas gerações de profissionais, entre eles, os professores e professoras de diferentes segmentos da Educação. 


\section{REFERÊNCIAS}

ALMEIDA, Laura Helena Jamelli de. Cartas em três atos: Paulo Freire, Angel Vianna e o cotidiano escolar. 2016. 154 f. Dissertação (Mestrado em Educação) - Universidade de Sorocaba, Sorocaba, SP, 2016.

ALMEIDA, Patrícia Neves de. O cotidiano escolar profanado com os jogos teatrais: o caso da escada. 2014. 98 f. Dissertação (Mestrado em Educação) - Universidade de Sorocaba, Sorocaba, SP, 2014.

ALVES, Nilda; GARCIA, Regina Leite. (Org.). O sentido da escola. Rio de Janeiro: DP\&A, 2000.

ALVES, Nilda. A formação com as imagens. Revista Interinstitucional Artes de Educar, Rio de Janeiro, v. 2, n. Especial (Vozes da Educação), p. 235-252, jun./ out. 2016.

ALVES, Nilda; GARCIA, Alexandra; OLIVEIRA, Inês Barbosa. (Org.). Nilda Alves: praticantepensante de cotidianos. Belo Horizonte: Autêntica Editora, 2015.

ALVES, Nilda Guimarães; FERRAÇO, Carlos Eduardo; GOMES, Marco Antonio O. Os cotidianos - espaçostempos de resistência e criação. Currículo sem Fronteiras, Rio de Janeiro, v. 19, n. 3, p. 1026-38, set./dez., 2019.

BARCELOS, Valdo Hermes de Lima. Por uma Educação Ambiental nos Trópicos: Interculturais e Antropofagia. Santa Cruz do Sul. In: PREVE, Ana Maria Hoepers; GUIMARÃES, Leandro Belinaso; BARCELOS, Valdo; LOCATELLI, Julia Schadeck. (Org.). Ecologias inventivas: conversas sobre a educação. Santa Cruz do Sul: EdUnisc, 2012. p. 98-120.

BARCHI, Rodrigo. As pichações nas escolas: uma análise sob a perspectiva da educação ambiental libertária. 2006. 137 f. Dissertação (Mestrado em Educação) - Universidade de Sorocaba, Sorocaba, SP, 2006.

BUARQUE, Chico. Cotidiano. Rio de Janeiro: Philips Records: 1971. [Música]. Disponível em: https://www.youtube.com/watch?v=dHYOVuq_Fco\&list=OLAK5uy_kSp2kBhC5BFcp H8B6hQe8M_5fXIWUcvq4. Acesso em: 13 maio 2020.

CATUNDA, Marta. A, B, C, de encontros sonoros: entre cotidianos da educação ambiental. 2013. 293 f. Tese (Doutorado em Educação) - Universidade de Sorocaba, Sorocaba, SP, 2013.

CERTEAU, Michel. A invenção do cotidiano: artes de fazer. Petrópolis: Vozes, 1998.

DELEUZE, Gilles. O abecedário de Gilles Deleuze: uma realização de Pierre-André 
Boutang. Paris: Éditions Montparnasse, 1988. Disponível em: https://www.facebook. com/haluznasanalises/videos Acesso em: 3 set. 2019.

DELEUZE, Gilles. Lógica do sentido. São Paulo: Perspectiva, 2007.

FALCÃO, Maria José Braga. A professora de nada - na consciência da ausência uma presença possível: arte no espaço e tempo do cotidiano escolar. 2015. 230 f. Tese (Doutorado em Educação) - Universidade de Sorocaba, Sorocaba, SP, 2015.

FERRAÇO, Carlos Eduardo. Currículos em redes. Curitiba: CRV Editora, 2016.

FREIRE, Paulo. Educação como prática de liberdade. 21. ed. Rio de Janeiro/São Paulo: Paz e Terra, 1992.

FREIRE, Paulo. Pedagogia da autonomia: saberes necessários à prática educativa. 56. ed. Rio de Janeiro/São Paulo: Paz e Terra, 2018.

FREIRE, Paulo. Pedagogia do oprimido. 71. ed. Rio de Janeiro/São Paulo: Paz e Terra, 2019.

GALLO, Silvio. Transversalidade e educação: pensando uma educação não-disciplinar. In: ALVES, Nilda; GARCIA, Regina Leite. (Org.). O sentido da escola. Rio de Janeiro: DP\&A, 2000. p. 17-40.

GERMANO, Marcia Aparecida Luna Rodrigues. Narrativas de idosos sobre a escola: uma leitura freireana. 2006. 133 f. Dissertação (Mestrado em Educação) - Universidade de Sorocaba, Sorocaba, SP, 2006.

GLISSANT, Édouard. Introdução a uma poética da diversidade. Juiz de Fora: Editora UFJF, 2005.

GODOY, Ana. A menor das ecologias. São Paulo: EDUSP, 2008.

GOERGEN, Pedro. Formação integral do ser humano: apontamentos sobre estética e educação. In: ROMAGUERA, Alda Regina Tognini; PIMENTA, Maria Alzira de Almeida (Org.). Univer-Cidade em encontros: educação, cultura e arte. Sorocaba: Eduniso, 2017. p. 225-50.

GUATTARI, Félix. As três ecologias. Tradução de Maria Cristina F. Bittencourt. 21. ed. Campinas: Papirus, 2011.

GUIMARÃES, Leandro Belinaso; KRELLING, Aline Gevaerd; PEREIRA, Juliana Cristina; DAL PONT, Karina Rousseng. Ecologias Inventivas: experiências das/nas paisagens. Curitiba: Editora CRV, 2015. 
HARDT, Michel; NEGRI, Antonio. Bem-estar comum. Rio de Janeiro: Editora Record, 2016.

HATOUM, Milton. Um solitário à espreita. [Crônicas]. São Paulo: Cia das Letras, 2013.

LIMA, Pedro Gomes. A educação menor para ser feliz: "piolhos" e "piolhiferações" no cotidiano escolar infantil. 2014. 119 f. Dissertação (Mestrado em Educação) - Universidade de Sorocaba, Sorocaba, SP, 2014.

MACHADO, Carmem Silva. Cotidiano escolar e arte: pedagogia do (des)encontro. 2019. 287 f. Tese (Doutorado em Educação) - Universidade de Sorocaba, Sorocaba, SP, 2019.

MACHADO, Carmem Silva. Inspiração, conteúdo e leveza: Pina Bausch adentra o cotidiano escolar. 2014. 273 f. Dissertação (Mestrado em Educação) - Universidade de Sorocaba, Sorocaba, SP, 2014.

MARTINS, Nataliane Isabela Oliveira. Ritmos de pensamento: rastros de cotidianoseducação. 2019. 247 f. Dissertação (Mestrado em Educação) - Universidade de Sorocaba, Sorocaba, SP, 2019.

RAMOS, Andreia Teixeira. Mulheres no congo do Espírito Santo: práticas de re-existência ecologista com os cotidianos escolares. 2018. 319 f. Tese. (Doutorado em Educação) Universidade de Sorocaba, Sorocaba, SP, 2018.

REIGOTA, Marcos; PRADO, Bárbara H. S. (Org.). Educação Ambiental: utopia e práxis. São Paulo: Cortez, 2008.

REZENDE, Ana R. A Educação Infantil como universo de pesquisa: teses e dissertações do Programa de Pós-Graduação em Educação da UNISO (1998-2015). 2016. 104 f. Dissertação (Mestrado em Educação) - Universidade de Sorocaba, Sorocaba, SP, 2016.

ROMAGUERA, Alda Regina Tognini; ANDRADE, Elenise Cristina Pires. Problematizar pesquisas e educações: fissuras metodológicas em tons de criação. Revista Ensaios Pedagógicos, Sorocaba, SP, v. 4, n. 01, p. 17-26, jan./abr. 2020.

SILVA, Ariane Diniz. Cartas para Paulo Freire e sua rede: o cotidiano de extensão em uma universidade comunitária. 2017. 264 f. Tese (Doutorado em Educação) -Universidade de Sorocaba, Sorocaba, SP, 2017.

SINTO, Carmensilvia Maria. Entre músicas cotidianas: manifestações musicais praticadas no cotidiano escolar. 2013. 126 f. Dissertação (Mestrado em Educação) - Universidade de Sorocaba, Sorocaba, SP, 2013. 
SPINK, Mary Jane Paris (Org.). Práticas discursivas e produção de sentidos no cotidiano. Rio de Janeiro: Centro Edelstein de Pesquisas Sociais, 2013. [Edição Virtual].

SPINK, Mary Jane Paris. Viver em áreas de risco: reflexões sobre vulnerabilidades socioambientais. São Paulo: Editora Educ, 2018.

\section{Sobre os autores:}

Ana Cristina Silva: Graduada em Pedagogia pelo Instituto Superior de Educação do Paraná. Doutora e mestre em Educação pela Universidade de Sorocaba/ UNISO. Professora da Educação Básica na rede Municipal de Sorocaba/SP. E-mail: anacbaladelli@gmail.com Orcid: http://orcid.org/0000-0002-2755-0059

Alda Romaguera: Doutora e mestre em Educação pela Universidade Estadual de Campinas. Graduada em Pedagogia pela mesma universidade. Pesquisadora do Programa de pós-graduação em Educação/UNISO. E-mail:aldaromaguera@gmail.com, alda.romaguera@prof.uniso.br, Orcid: http://orcid.org/0000-0002-8932-4778

Magda Bellini: Doutoranda e mestre em Educação pela Universidade de Sorocaba/ UNISO. Graduada em história pela Faculdade de Filosofia Ciências e Letras de Sorocaba e em Pedagogia pela Faculdade de Filosofia, Ciências e letras de Botucatu. Diretora de escola da rede municipal de São Roque/SP. E-mail: magdacfb@yahoo.com.br, Orcid: http://orcid.org/0000-0001-5221-8034

Vinícius Santos: Graduado em Psicologia pela Universidade Paulista/Campus Sorocaba/ SP. Psicólogo e professor da educação básica. E-mail: viniciusfsantos07@gmail.com, Orcid: http://orcid.org/0000-0002-7071-9833

\section{Recebido em: 19/08/2020 Aprovado em: 31/01/2021}


